\title{
Replicase mediated resistance against Potato Leafroll Virus in potato Desirée plants
}

\author{
NICOLE EHRENFELD ${ }^{1}$, EDUARDO ROMANO ${ }^{2}$, CAROLINA SERRANO $^{1}$ and \\ PATRICIO ARCE-JOHNSON ${ }^{1}$
}

\author{
${ }^{1}$ Laboratorio de Bioquímica, Departamento de Genética Molecular y Microbiología, Facultad de Ciencias \\ Biológicas, Pontificia Universidad Católica de Chile, Santiago, Chile. \\ ${ }^{2}$ EMBRAPA, Brasilia, Brasil.
}

\begin{abstract}
Potato leafroll virus (PLRV) is a major menace for the potato production all over the world. PLRV is transmitted by aphids, and until now, the only strategy available to control this pest has been to use large amounts of insecticides. Transgenic approaches involving the expression of viral replicases are being developed to provide protection for plants against viral diseases. The purpose of this study was to compare the protection afforded by the differential expression of PLRV replicase transgene in potato plants cv. Desirée. Plants were genetically modified to express the complete sense PLRV replicase gene. Two constructions were used, one containing the constitutive 35SCaMV promoter and the other the phloem-specific RolA promoter from Agrobacterium rhizogenes. Transgenic plants were infected with PLRV in vitro, using infested aphids. In plants in which 35SCaMV controlled the expression of the PLRV replicase gene, signs of infection were initially detected, although most plants later developed a recovery phenotype showing undetectable virus levels 40 days after infection. In turn, those plants with the RolA promoter displayed an initial resistance that was later overcome. Different molecular mechanisms are likely to participate in the response to PLRV infection of these two types of transgenic plants.
\end{abstract}

Key terms: Replicase, PLRV, replicase mediated resistance, RolA promoter, transgenic potatoes

\section{INTRODUCTION}

Potato Leafroll Virus (PLRV) causes devastating effects on potato production. This virus primarily affects the aerial tissues of potato plants, causing the stem and apical leaves to roll. Unlike other viruses, PLRV is exclusively found in phloem tissues and causes necrosis and abnormal callose accumulation in the vascular system. PLRV is propagated by aphid vectors from plants originated from infested tubers.

According to its genetic structure, PLRV belongs to the Luteovirus subgroup 2. This virus possesses a $5.9 \mathrm{kDa}$ genome consisting of a single strand RNA molecule with plus orientation that encodes six open reading frames (ORF) (van der Wilk et al., 1997). Three of these frames are located near the 3'end and encode, through subgenomic RNA molecules, the $23 \mathrm{kDa}$ coat protein (CP) (Van der Wilk et al., 1989), a $17 \mathrm{kDa}$ floematic movement protein (MP) (Sokolova et al., 1997) and a $56 \mathrm{kDa}$ protein involved in the virus/vector aphid interaction (Chay et al., 1996). The ORFs located near the $5^{\prime}$ end of the genome encode directly from genomic RNA several proteins (Matthews, 1991). The protein VPg and a $70 \mathrm{kDa}$ protein (van der Wilk et al., 1997) is encoded by the first ORF (Gorbalenya et al., 1989). The second ORF encodes a $28 \mathrm{kDa}$ protein of unknown function, whereas the third is thought to encode a $69 \mathrm{kDa}$ replicase (Koonin, 1991).

Corresponding author: Patricio Arce-Johnson, Laboratorio de Bioquímica, Departamento de Genética Molecular y Microbiología, Facultad de Ciencias Biológicas,Pontificia Universidad Católica de Chile, Santiago, Chile.

Telephone: (56-2) 686-2897 - Fax: (56-2) 222-5515. E-mail: parce@ genes.bio.puc.cl 
PLRV-resistant potato lines have been described, most of which are Chilean wild type lines (Contreras, 1984). Unfortunately these lines are difficult to cultivate and even more difficult to cross with lines that are economically significant (Hermsen et al., 1981). Further efforts have since been made to obtain virus resistant plants through transgenic manipulations. Transgenic resistance has been used successfully with other viruses, such as the Tobacco Mosaic Virus (TMV). In 1986 Abel et al. described the production of transgenic tobacco plants resistant to TMV that contain the viral gene of the TMV coat protein $(\mathrm{CP})$. Subsequent reports confirmed the value of transgenic plants in controlling infection caused by different viruses (Miller and Hemenway, 1998; Dunwell et al., 2001). However, in potato, the expression of the CP gene from PLRV affords only partial resistance (Kawchuk et al., 1990). Similarly, the expression of the PLRV 17 $\mathrm{kDa}$ movement protein reduced PLRV infestation by a mere $30 \%$ and conferred partial resistance to potato virus $\mathrm{Y}$ (Tacke et al., 1996).

Transformation of plants with viral replicase has been shown to produce very effective and stable resistance (Canto and Palukaitis, 1999). This approach has been used with replicases from different viruses, such as the Cucumber Mosaic Virus (CMV) (Carr et al., 1994), the Tobacco Mosaic Virus (Golemboski et al., 1990) or the Potato Virus X (Longstaff et al., 1993). Although the resistance induced by replicase is high and stable in most cases (de Haan, 1997), it is very specific and does not afford protection to related viruses (Palukaitis and Zaitlin, 1997). It has been suggested that there is no single resistance mechanism involved in replicase-induced resistance. In fact, in some cases, the resistance observed does not seem to involve the expression of the replicase protein (Mueller et al., 1995; Tenllado et al., 1996).

In potato, high levels of resistance to PLRV have been induced by the expression of diverse variants of the replicase gene from PLRV driven by the CaMV35S promoter from the cauliflower mosaic virus
(Thomas et al., 2000). Moreover, Colorado potato beetle- and PLRV-resistant potatoes were created by Monsanto and recently released and accepted in Canada and the U.S. for human consumption (http:// www.hc-sc.gc.ca/food-aliment/mh-dm/ofbbba/nfi-ani/e_ofb-099-127-b.html). Due to the constitutive nature of CaMV35S in these plants, the replicase transgene is expressed in all tissues. This widespread expression of transgenes has been postulated to affect the normal metabolism of plants (Graham et al., 1997).

To prevent the problems derived from the constitutive expression of the transgene, and to determine whether tissue specific gene expression of PLRV replicase gene is sufficient to confer resistance to PLRV, we produced transgenic potato plants that express a PLRV replicase gene driven by the promoter RolA from Agrobacterium rhizogens, specific to vascular tissues. The replicase expression and induction of resistance in transgenic Desirée potato line was compared with that of transgenic plants in which the constitutive promoter $\mathrm{CaMV}$ $35 \mathrm{~S}$ drove the replicase gene.

\section{METHODS}

All gene constructs reported here are based on the high copy number plasmid pGEMPOL, derived from vector pGEM-T (Promega Co.) that contains the $1.8 \mathrm{~kb}$ fragment encoding PLRV replicase $(69 \mathrm{kDa})$, cloned into restriction sites BamHI/KpnI.

Plasmid pGEMPOL was restricted with KpnI. This site was blunted with Klenow enzyme and the fragment corresponding to PLRV replicase released with restriction enzyme BamHI.

The $1.8 \mathrm{~kb}$ fragment was cloned into vector pBI121 (Clontech Laboratories Inc., USA) using sites BamHI/KpnI (Klenow), downstream of promoter $35 \mathrm{~S}$ from CaMV, and replacing gene uidA. The resulting vector, called p35SPOL, also possesses the gene nptII (neomycin phosphotransferase), that confers resistance to kanamycin. The $1.8 \mathrm{~kb}$ fragment was also cloned into sites BamHI/KpnI (Klenow) of plasmid pBRAGUS. pBRAGUS is a pBI121 
derivative that contains the promoter RolA from Agrobacterium rhizogenes (Carneiro and Vilaine, 1993) instead of promoter 35S, to drive the expression of gene uidA. The resulting vector, called vector pBRAPOL, allows the expression of PLRV replicase transcripts under the transcriptional control of rolA promoter. The structures of these two constructions were confirmed through sequencing, following the "dsDNA Cycle Sequencing System” protocol (Gibco BRL, Inc., USA), as described by the manufacturers. Sequencing efforts relied on the use of primer STAR-INV 5'-TGT TTT GGC GGG CGG TGC-3', which allows sequencing from the center of the replicase gene toward the promoter.

Verified binary vectors p35SPOL and pBRAPOL plus control plasmids pBI121 and pBRAGUS were mobilized into Agrobacterium tumefaciens LBA4404 (Hoekema et al., 1983) through electroporation. Genetic transformation procedures were carried out in plants and mini-tubers from Solanum tuberosum cultivar Desirée. The plants were provided by the Laboratorio de Micropropagación de la Subestación La Pampa, Osorno, Chile, of the Instituto Nacional de Investigaciones Agropecuarias (INIA). Plants were propagated in vitro, maintained in sterile medium MS (Murashige and Skoog, 1962), and grown in growth chambers under controlled conditions (temperature range $20-25^{\circ} \mathrm{C}$; 16-h daylight photoperiod and light intensity of $60 \mu \mathrm{Em}^{-2} \mathrm{~s}^{-1}$ ).

Genetic transformation of potato with PLRV replicase

We used internodes from potato plant cv. Desirée maintained under in vitro conditions for 4-6 weeks.

A. tumefaciens strain LBA4404 transformed with either plasmid p35SPOL or pBRAPOL was used for transformation experiments. Potato plants were also transformed with A. tumefaciens containing the control plasmids pBI121 or pBRAGUS, carriers of the gene uidA, which encodes the enzyme $\beta$-glucuronidase (GUS). $A$. tumefaciens infection and subsequent selection of transgenic plants was carried out according to An et al. (1986). Kanamycin resistant, ELISA NPT II positive independent clones were maintained in vitro, in medium MS supplemented with $50 \mathrm{mg} / \mathrm{L}$ of kanamycin (kan) and $300 \mathrm{mg} / \mathrm{L}$ of cefatoxime (cef), under growing conditions as previously described. The transgenic lines were named according to their respective genes and promoters. For instance, $35 \mathrm{~S}$ replicase lines were labeled $35 \mathrm{~S} 01,35 \mathrm{~S} 12$, the lines containing the promoter rolA and the GUS gene: pBRAGUS1, pBRAGUS2, etc; and those containing the promoter rolA and the replicase gene RolA1, RolA5, etc.

\section{Transgene detection in transformed plants}

Genomic DNA was isolated from leaves of transgenic and non-transgenic plants following standard CTAB procedures (Ausubel et al., 1990). A $1.8 \mathrm{~kb}$ fragment was targeted for PCR analyses using genomic DNA, using primers STAR-POL 5'-GCACCGCCCGCCAAAACA-3' and STOP-POL 5'-GTGGTGGCACTCGGAA CC-3'. Both primers show a $100 \%$ sequence homology to the PLRV replicase gene. Amplifications were conducted in a "Programmable Thermal Controller PTC100" (MJ Research, Inc.) and the PCR cycle was as follows: 1.) DNA denaturation: $95^{\circ} \mathrm{C}, 3 \mathrm{~min} ; 2$.) $\mathrm{DNA}$ denaturation: $94^{\circ} \mathrm{C}, 45 \mathrm{sec}$. 3.) Primer annealing: $65^{\circ} \mathrm{C}, 30 \mathrm{sec} ; 4$ 4) DNA polymerization: $72^{\circ} \mathrm{C}$, min; 5.) Steps $2-4$ were repeated 30 times; 6.) Incomplete polymerization synthesis: $72^{\circ} \mathrm{C}, 10 \mathrm{~min}$; 7.) End and soaking at a $4^{\circ} \mathrm{C}$.

For Southern blotting procedures, $10 \mu \mathrm{g}$ of genomic DNA were digested with restriction enzymes BamHI and $K p n \mathrm{I}$ to verify fragment insertion and with restriction enzyme HindIII to determine the transgene copy number. Restricted fragments were separated in 1\% agarose gels and transferred onto Zeta-Probe®, nylon membranes (BioRad Laboratories, California, USA), following procedures reported by Ausubel et al. (1990). A $1.8 \mathrm{~kb}$ fragment obtained from the PLRV replicase gene amplification with 
primers STAR-POL and STOP-POL was used as probe to analyze the insertion of the replicase gene into the potato genome. To determine the copy numbers, a $300 \mathrm{bp}$ fragment derived from the PLRV replicase gene amplified with PCR primers $\triangle \mathrm{X}-\mathrm{STAR}$ $5^{\prime}$-AGCTCACCGACGGCCTTC-3' and $\Delta X$ STOP 5'GTTGACCGGAACGGCGGAG-3', was used. Probes were labeled with $\left(\alpha_{-}{ }^{32} \mathrm{P}\right)$ dCTP using the commercial kit Prime-aGene Labeling System (Promega Corporation, Madison, USA). Membrane hybridizations followed procedures reported by Ausubel et al. (1990). After hybridization, membranes were washed with $2 \mathrm{X}$ SSPE, $0.1 \%$ SDS until specific radioactivity was detected but only in areas where RNA was located. Hybridization results were visualized through autoradiographic procedures, using Kodak XAR-2 film exposed for $2-3$ days at $-70^{\circ} \mathrm{C}$.

\section{Transgene expression in transformed plants}

Total RNA was isolated from frozen potato leaves as described in Logemann et al. (1987). $30 \mu \mathrm{g}$ of total RNA were loaded for Northern Blot experiments, using $1 \%$ formaldehyde-agarose gels. RNA fragments were separated by electrophoresis and then transferred onto Zeta-Probe ${ }^{\circledR}$, nylon membranes (Bio-Rad Laboratories, California, USA) as reported by Ausubel et al. (1990). RT-PCR was carried out according to the recommendations of commercial kit "SUPERSCRIPT" Preamplification System for First Strand cDNA Synthesis" (Gibco BRL, Inc., USA) was used to generate the probe used in Northern blot experiments. Since the replicase mRNA creates several secondary structures, the protocol recommended for GC rich sequences (High GC RT) was followed. cDNA was created with oligonucleotide STOP-POL, and primers used for PCR amplification were STOPPOL and $\triangle \mathrm{X}-\mathrm{STAR}$. Hybridizations with the $1.6 \mathrm{~kb}$ probe were carried out in a polyetilenglycol- and formamide-containing buffer, as described by Ausubel et al. (1990). Membranes were washed with 2X SSC and $0.1 \% \mathrm{SDS}$ for $20 \mathrm{~min}$ at $50^{\circ} \mathrm{C}$ and then with $0.2 \mathrm{X}$ SSC, $0.1 \%$ SDS $0,1 \%$ for $10 \mathrm{~min}$ at $50^{\circ} \mathrm{C}$. Hybridization results were visualized through autoradiographic procedures, using Kodak XAR-2 film exposed for $2-3$ days at $-70^{\circ} \mathrm{C}$.

Tissue specific expression of PLRV replicase and PLRV resistance

In order to assess tissue-specific expression of the PLRV replicase gene, in situ hybridization analyses were conducted in transgenic plants according to the protocol reported by Pereda et al. (2000).

PLRV-carrying aphids and plants grown in vitro were used to conduct viral infection with transgenic and control plants. Virus presence and accumulation was assessed 35 days after infection. Absorbance at $405 \mathrm{~nm}$ was used to determine PLRV capside protein relative accumulation using a commercial kit direct ELISA, alkaline phosphatase label, anti-PLRV (AGDIA Inc., Elkhart, USA).

\section{RESULTS}

Genetic transformation of potato with the $P L R V$ replicase gene

Figure 1 shows cassettes p35SPOL and pBRAPOL inserted between the right and left borders of binary plasmid pBIN19 (Bevan, 1994), used to transform potato. Sequencing and restriction analyses of its structural element, the PLRV replicase gene, confirmed $100 \%$ homology with viral sequences previously reported (data not shown).

Potato plants of cv. Desirée were transformed with plasmids p35SPOL and pBRAPOL, both carriers of selection gene nptII. Since potato roots are extremely sensitive to kanamycin, root forming potato plantlets when grown in kanamycin containing culture medium were considered transgenic.

Genetic transformation experiments produced 15 and 5 p35SPOL and pBRAPOL transgenic lines respectively. These transgenic lines, plus another created with plasmid pBI121 (GUS positive 


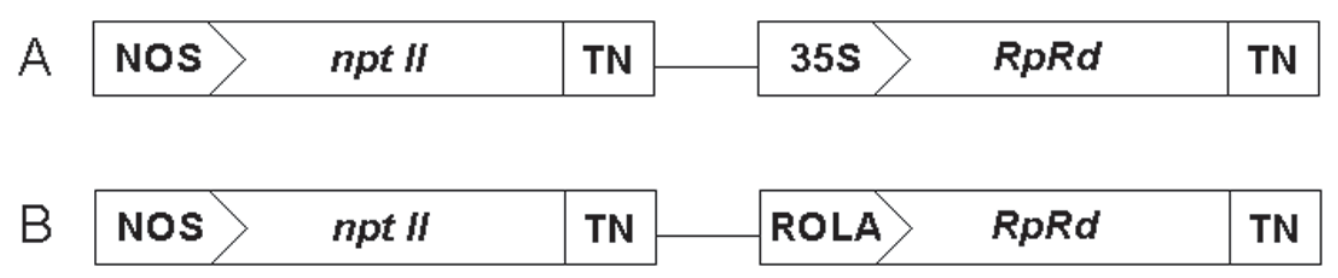

Figure 1. Constructions of PLRV replicase (RpRd) used to transform potato plants.

All the constructions were performed in pBIN19 plasmid (Bevan, 1984). A single copy of the RpRd gene was inserted between the left and the right borders of T-DNA. The constructions also included the nptII gene for kanamicine resistance, inserted between the NOS promoter (NOS) and the NOS terminator (TN), both from the Nopaline Synthase gene. A.) p35SPOL construction: the PLRV replicase gene is located downstream of $35 \mathrm{~S}$, the constitutive promoter of Cauliflower Mosaic Virus. B.) pBRAPOL construction: the PLRV replicase gene is located downstream of ROLA, the phloematic expression promoter of $A$. rhizogenes.

control) were analyzed through ELISA to detect the presence of the neomycin phosphotransferase II enzyme (NPTII). They all tested NPTII positives, with the only exception of WT plants (negative control), suggesting that the recombinant $\mathrm{T}$ DNA carrying antibiotic resistance was inserted and successfully expressed in transformed plants.

Molecular analyses of potato transgenic clones. PCR and Southern blot analyses

ELISA NPTII positive potato lines were also analyzed through PCR amplifications and Southern blot hybridizations in order to verify the presence of the PLRV replicase gene. PCR analyses showed that all plants identified as NPTII positive presented a $1.6 \mathrm{~kb}$ fragment. Restriction analyses confirmed that this fragment was the full PLRV replicase gene (data not shown). Southern blot hybridizations were then conducted in order to confirm integration of the PLRV replicase gene into the genome of potato in 20 transgenic lines (data not shown). All lines proved to be carriers of the PLRV replicase gene, confirming results obtained through PCR amplification and ELISA NPT II. This body of evidence suggests the presence of the complete PLRV replicase gene existing in cassettes p35SPOL and pBRAPOL in transgenic potato plants. Copy number analyses in 10 randomly selected lines identified 5 single copy plants, and 3 and 2 plants with 2 and 3 gene copies respectively (Table I).

\section{Northern blot and RT-PCR analyses}

Expression analyses of mRNA from the PLRV replicase gene were also conducted to determine its transcriptional activity and also to relate its expression levels with the degree of resistance to PLRV infection Northern Blot experiments showed a $1.8 \mathrm{~kb}$ transcript in 6 of the 12 lines analyzed. Transgenic lines RolA3, 35S16, and 35S21 shown in lanes 4, 5 and 6 of Figure 2 respectively present a positive signal corresponding to the expected transcript, although at different intensities. In order to be able to detect PLRV replicase gene transcripts at a higher sensitivity level and to avoid false positives, RT-PCR was also conducted. Since less tissue-specific expression was expected in transgenic plants expressing promoter RolA, a double load of RNA was used in transcriptase reverse reactions in those transgenic lines derived from plasmid pBRAPOL.

Most transgenic lines showed a transcript corresponding to the transgene under study. PLRV replicase gene transcripts were observed in lines $35 \mathrm{~S} 18$, 35S22 and RolA8, which tested negative in 
A

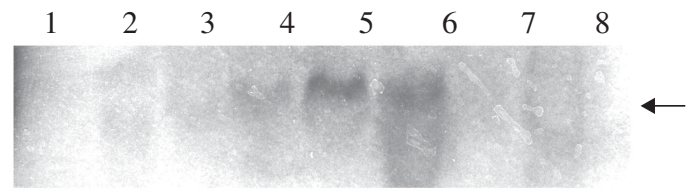

B

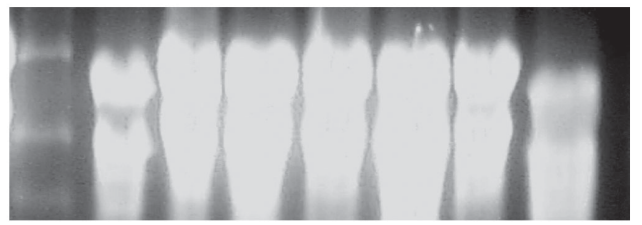

Figure 2. Expression of PLRV replicase gene in transgenic potato plants.

$30 \mu \mathrm{g}$ of total RNA extracted from transformed potato plants were hybridized with a $300 \mathrm{nt}$ DNA probe complementary to the $3^{\prime}$ end of the PLRV replicase gene, labeled with $\mathrm{P}^{32}$-dCTP. The arrow shows a $1.8 \mathrm{~Kb}$ fragment that corresponds to a PLRV replicase transcript. Lanes: 1) GibcoBRL 0,24-9,5 Kb RNA Ladder; 2) WT plant; 3) Transgenic line; 4) Line RolA3; 5) Line $35 \mathrm{~S} 16$; 6) Line $35 \mathrm{~S} 21$; 7) Line $35 \mathrm{~S} 18$; 8) Line 35S19. Row B: Load controls stained with Etidium Bromide.

Northern blot experiments (Table I). Nevertheless, none of these experimental approaches was able to detect the PLRV replicase gene transcript in lines $35 \mathrm{~S} 19$, 35S25, and RolA1, although they tested positive in Southern blot experiments using a PLRV replicase gene probe (Table I).

\section{In situ hybridization studies}

Leaf tissues were used to conduct in situ hybridization experiments, aiming to assess whether the expression patterns of PLRV replicase gene followed the tissue specificity patterns expected from the promoters transgenic plants were derived from. Transgenic plants expressing PLRV replicase gene under the transcriptional control of promoter $35 \mathrm{~S}$ presented a transcript across all leave tissues, including mesophyll and petioles (Figure 3B), whereas PLRV replicase gene transcripts were only observed in vascular tissues in transgenic plants expressing the

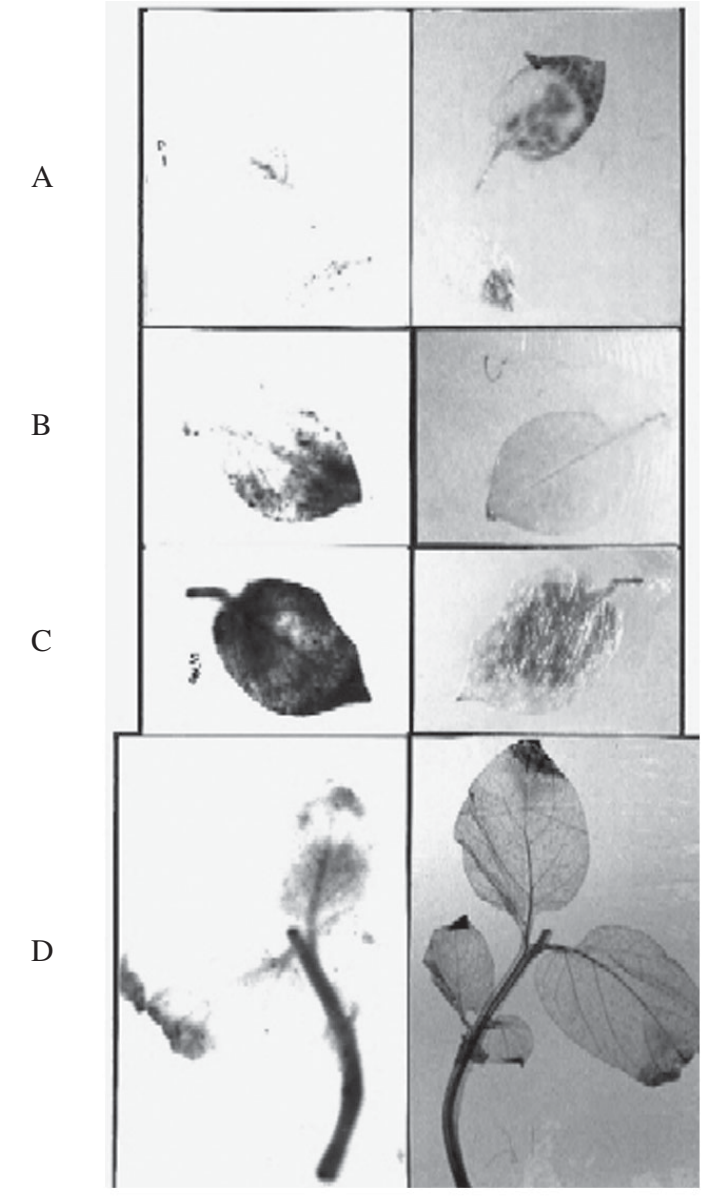

Figure 3. Different patterns of expression of replicase gene in transformed plants.

For in situ hybridization experiments, leaves were permeabilized with proteinase $\mathrm{K}$, according to Pereda et al (2000) and then hybridized with a 300 nt DNA probe complementary to the 3'end of the PLRV replicase gene, labeled with $\mathrm{P}^{32}$ dCTP. Left panels show the autoradiographic images. Right panels show optic images of the same leaves after treatment with the radioactive A) negative control (non-infected WT plant); B) plant transformed with p35SPOL; C) WT plant infected with PLRV; D) Plant transformed with pBRAPOL.

PLRV replicase gene under the transcriptional control of promoter RolA (Figure 3D). Similar results were observed when the tissue specificity of reporter gene GUS under the transcriptional control of these promoters was analyzed (data not shown). 
Virus resistance in transgenic plants challenged with PLRV

PLRV-carrying aphids were used to conduct in vitro infestation studies in PLRV replicase gene transgenic plants. The accumulation of PLRV CP in challenged plants was assessed 35 days after viral infection (dpi). Figure 4 shows the characteristic pattern of viral capside protein accumulation in transgenic and non transgenic (control) lines challenged with PLRV. Three different response types in transgenic plants were observed. The first phenotype was plants susceptible to PLRV infection (i.e. line 35S21). Large amounts of virus were observed in these plants 30 dpi. In the second phenotype, initial resistance to PLRV infection was seen, although viral resistance decayed and viral titer significantly increased after 40 days. This pattern was exclusively observed in a transgenic line carrying the RolA1 promoter (Figure 4). The third and most frequently observed response consisted of an initial infection followed by viral infection recovery 25 days after infection (i.e. lines 35S16 and 35S25 in Figure 4).

Table I summarizes the resistance to PLRV observed in transgenic potato lines. Neither a clear relationship between transgene expression detected through Northern experiments or RT-PCR and PLRV resistance, nor a consistent relationship between transgene copy number and virus resistance were observed (Table I).

\section{DISCUSSION}

Genetic transformation of potato plants with the PLRV replicase gene

We report here the successful development of transgenic plants of potato cv. Desirée that express the PLRV replicase gene exclusively in phloem tissue. The tissuespecificity was attained by the use of the promoter RolA from Agrobacterium rhizogenes, which is expressed exclusively

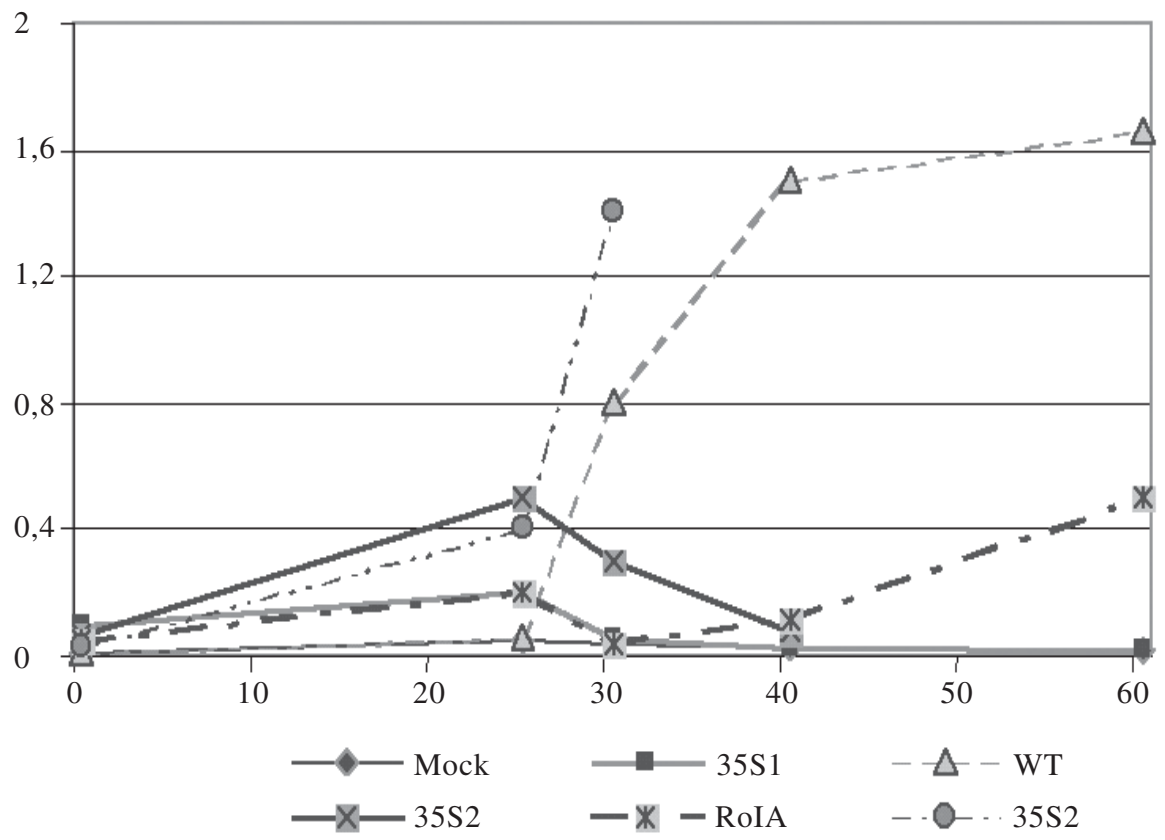

Figure 4. Time course of PLRV coat protein accumulation in transgenic potato plants infected with PLRV

Plants were infected in vitro by means of aphids contaminated with PLRV. The accumulation of PLRV coat protein was assayed by indirect ELISA using antibodies against PLRV and anti IgG antibodies labeled with alkaline phosphatase. Day 0 corresponds to infection day. Mock group corresponds to noninfected, non-transformed plants. WT corresponds to non-transformed plants infected with PLRV. 
TABLE I

PLRV resistance in potato transgenic plants and its relationship with transgene expression and copy number

\begin{tabular}{lcccc}
\hline $\begin{array}{l}\text { Transgenic } \\
\text { Line }\end{array}$ & $\begin{array}{c}\text { Transgene } \\
\text { Copy number }\end{array}$ & $\begin{array}{c}\text { Replicase gene } \\
\text { Northern blot }\end{array}$ & $\begin{array}{c}\text { Replicase gene } \\
\text { RT-PCR }\end{array}$ & $\begin{array}{c}\text { PLRV } \\
\text { Resistance }\end{array}$ \\
\hline $35 \mathrm{~S} 12$ & 1 & + & + & + \\
$35 \mathrm{~S} 16$ & 3 & + & + & +++ \\
$35 \mathrm{~S} 17$ & 1 & + & + & + \\
$35 \mathrm{~S} 18$ & 2 & - & + & + \\
$35 \mathrm{~S} 19$ & 1 & - & + & ++ \\
$35 \mathrm{~S} 20$ & 1 & + & + & + \\
$35 \mathrm{~S} 21$ & 2 & + & + & - \\
$35 \mathrm{~S} 22$ & 3 & - & - & + \\
$35 \mathrm{~S} 25$ & $\mathrm{ND}$ & - & - & +++ \\
RolA1 & 2 & - & + & + \\
RolA3 & 1 & + & + & - \\
RolA8 & ND & - & + & + \\
\hline
\end{tabular}

+ indicates gene transcript presence, and - gene transcript absence in replicase gene RT-PCR column. In the PLRV resistance column, +++ corresponds to a viral accumulation equal or inferior to $15 \%$ of the titer observed in non-transformed plants at $30 \mathrm{dpi}$; ++ corresponds to a viral accumulation between $15 \%$ and $40 \%$ of the titer observed in non-transformed plants at $30 \mathrm{dpi}$; + corresponds to a viral accumulation between 40 and $65 \%$ of the titer observed in non-transformed plants at $30 \mathrm{dpi} ;+/$ - corresponds to a delay in viral accumulation during the 40 dpi period and a subsequent accumulation equal to that observed in non-transformed plants; - corresponds to a viral accumulation similar to that observed in observed in non-transformed plants. ND: Non-determined.

in vascular tissues (Carneiro and Vilaine, 1993). In contrast, when the promoter $35 \mathrm{~S}$ from the Cauliflower Mosaic Virus (CaMV) was used, replicase transcripts were detected in all tissues examined (Figure 3).

In naturally infected plants, the viral components of PLRV and other Luteovirus are found exclusively in sieve elements, companion cells, and phloem parenchymatic cells (Kojima et al., 1969; Derrick and Barker, 1997). We therefore aimed to develop resistant plants in which the expression of the PLRV transgenes was restricted to the tissues susceptible to this virus.

Our transgenic plants carried, in most cases, a single copy of the replicase gene. However, some plants with two and three copies were also obtained (Table I). Despite having the same number of gene copies (i.e. one), differing levels of PLRV replicase messengers were found in 12 of the 20 transgenic lines analyzed (3 RolA lines and
$935 \mathrm{~S}$ lines). Transgenic plants carrying the promoter $35 \mathrm{~S}$ had higher total levels of PLRV replicase messenger than plants carrying the ROLA promoter. RT-PCR experiments further confirmed the presence of the replicase gene in all transgenic plants that tested positive in the Northern blot (Table I). On the other hand, plants from lines RolA8, 35S18 and 35S22, which gave negative results by Northern blot analysis, tested positive for the replicase gene, as determined by RT-PCR (Table I). Line RolA1, 35S19 and 35S25 tested negative in both Northern blot and RT-PCR analyses. This negative result may indicate that the RolA1, 35S19 and 35S25 lines either do not express the PLRV replicase gene or have an expression level below the resolution of the methods used in this study. No clear relationships were found between the transgene copy number, the level of expression of the PLRV replicase gene, and 
the resistance to PLRV in transgenic plants, regardless of the promoter used for transformation. The fact that independent transgenic lines with independent insertions show similar resistant behavior but different molecular responses may indicate that different mechanisms are involved in this resistance.

\section{Analysis of resistance to PLRV infection in transgenic plants}

According to their response to PLRV infection (as indicated by the total viral titer), three clearly different phenotypes could be distinguished among the transgenic plants. The first phenotype (characteristic of transgenic lines 35S21, RolA3 and RolA8) was completely susceptible to viral infection. Viral accumulation in these lines was similar to that observed in non-transformed plants challenged with PLRV. These plants were susceptible to viral infection despite the fact that they expressed the replicase gene.

The second phenotype was only observed in line RolA1 and displayed initial resistance to the virus. When compared to the first phenotype, this line had lower levels of viral accumulation at all times during analysis. The viral titer was low and stable during the first 40 days after infection (dpi) and increased subsequently (50 and $60 \mathrm{dpi}$ ). However, it never reached the levels found in non-transgenic potato plants infected with PLRV (Figure 4).

The third phenotype corresponds to a previously-reported "recovery phenotype" (Tenllado et al., 1996). This phenotype was observed only in transgenic plants transformed with the promoter $35 \mathrm{~S}$ and was characteristic of $75 \%$ of the potato transgenic lines obtained. These plants showed variable degrees of recovery from viral infection (Table I, Figure 4).

No clear relationship was found between the phenotype of the plant and the expression of the replicase transgene. For instance, in plants with phenotype 1 , (RolA3, RolA8) the viral replicase gene is detected but no resistance is observed. A possible explanation for this is that the transcription of a single transgene might not produce a level of RNA transcript sufficient to activate the RNA surveillance system (Goodwin et al., 1996).

In the case of phenotype 2 plants (RolA1 line), a transient resistance to PLRV was seen despite the fact that no messengers of the PLRV replicase were detected (Table I). This may indicate that a post-transcriptional gene silencing (PTGS) process is involved. In the PTGS process, once a specific mRNA enters the cytoplasm, it is recognized by the RNA surveillance system and degraded. This phenomenon is observed in different organisms including plants, animals, and fungi (Waterhouse, 1999; Sijen and Kooter, 2000). When transgenic plants become infected with the virus that expresses the same sequence as the transgene, the mRNA, viral RNA, and transgene mRNA are degraded (Vaucheret and Fagard, 2001). Other studies show that PTGS degradation also occurs when the RNAs derived from the transgene are homologous to any plant mRNA present in the cytoplasm. Viruses are able to induce PTGS in plants, even in the absence of a homologous transgene (Llave et al., 2000). It is therefore possible that the introduction of the PLRV replicase gene into potato plants activates the RNA surveillance system that affects both transgene- and viralderived messengers. Thus, we postulate that PTGS is involved in the initial resistance of line RolA1 to PLRV infection.

The loss of the resistance in phenotype 2 plants (RolA1 line) is a puzzling finding. On the one hand, it might be the result of the end of the PTGS. In fact, PTGS has been reported to disappear after $40 \mathrm{dpi}$, particularly in meristematic tissues (Ruiz et al., 1998). On the other hand, the increase in the virus titer observed from 40 dpi on may result from the spread of viral particles to cells that are in close proximity with vascular tissues. This idea is based on the fact that even when PLRV is normally restricted to vascular tissues (Kojima et al., 1969; Derrick and Barker, 1997), viral particles have been shown to spread out of the vascular tissues and infect adjacent cells (Derrick and Barker, 1997). If this were the case in our RolA1 plants, it could be concluded that the cellular mechanisms 
responsible for the initial resistance observed were not present in the adjacent cells to prevent the replication of the viral particles. Based upon current evidence, it is not possible to determine which mechanism or mechanisms are involved.

In the case of phenotype 3 plants (transformed with the promoter $35 \mathrm{~S}$ ), their ability to recover from infection seems to have a complex relationship with the expression of the PLRV replicase gene. For example, lines 35S25 and 35S19 displayed a recovery response despite having no detectable levels of PLRV replicase messenger. This may indicate either that resistance is possible without replicase messengers or that these plants expressed replicase at levels undetected by our methods. In contrast, line $35 \mathrm{~S} 16$ had both a recovery response and replicase messengers (Table I). Thus, at least two possible recovery strategies are conceivable according to their dependence on transgene viral expression. The possibility of resistance in the absence of transgene transcripts is supported by the results of Vazquez-Rovere et al. (2001), who demonstrated the occurrence of PTGS in PLRV resistant potato plants transformed with PLRV replicase expressed by $35 \mathrm{~S}$ promoter.

The possibility that the PLRV replicase protein plays a role in the resistance observed in transgenic plants that express the replicase transcripts cannot be ruled out. This would be consistent with results found in transgenic potato plants infected with TMV or CMV viruses. In some plants infected with TMV that express resistance 8 days after inoculation, replicase proteins are thought to underlie the resistance response. Replicase transcripts are thought to mediate resistance during the first $7 \mathrm{dpi}$ (Goregaoker et al., 2000). On the other hand, resistance to $\mathrm{CMV}$ is seen in plants that express transcribed forms of CMV replicase, but not in those that express nontranscribed forms of the enzyme (Wintermantel and Zaitlin, 2000). This suggests that the transgene replicase would be necessary for an effective resistance.

In conclusion, with the use of the RolA promoter, we were able to produce transgenic potato plants that express the replicase gene exclusively in the phloem tissue. These plants displayed a transient resistance to PLRV infection and variable levels of replicase transcripts. On the other hand, plants transformed with the $35 \mathrm{~S}$ promoter expressed the replicase transcripts in all tissues and displayed long-lasting resistance to PLRV infection. The relationship between resistance and replicase expression was not clear. In fact, some transgenic plants transformed with RolA were resistant to infection but had no detectable levels of the replicase RNA. This may be the result of a post-translation gene silencing (PTGS) process. The relative role of the viral replicase messenger and protein in PLRV resistance remains to be determined.

Resistant PLRV lines have been created by Monsanto Co. using cultivar Russet Burbank. These lines are also resistant to CPB (Colorado potato beetle), and have been recently released and accepted in Canada and USA for human consumption (http://www.hc-sc.gc.ca/food-aliment/mhdm/ofb-bba/nfi-ani/e_ofb-099-127-b.html). As in our transgenic potato plants, the molecular process for PLRV resistance may be the possible gene silencing process involved in the replicase-mediated resistance.

Field experiments will be necessary to determine whether the transient resistance seen in RolA1 plants is sufficient to prevent the devastating effect of PLRV on potato production and to compare it with other natural or created PLRV-resistant potato lines.

\section{REFERENCES}

ABEL PP, NELSON RS, DE B, HOFFMANN N, ROGERS SG, FRALEY RT, BEACHY RN (1986) Delay of disease development in transgenic plants that express the tobacco mosaic virus coat protein gene. Sci 232: 738- 743

AN G, WARSON BD, CHIANG CC (1986) Transformation of tobacco, tomato, potato and Arabidopsis thaliana using binary $\mathrm{Ti}$ vector system. Plant Physiol 81: 301- 305

AUSUBEL FM, BRENT R, KINGSTON RE, MOORE DD, SEIDMAN JG, SMITH JA, STRUHL K (1990) Current protocols in Molecular Biology, $3^{\text {rd }}$ Edition, New York: Greene Publishing Associates and Wiley-Interscience

BEVAN M (1984) "Binary Agrobacterium vectors for plant transformation." Nucleic Acid Research 12(22), 87118720 . 
CANTO T, PALUKAITIS P (1999) Replicase-mediated resistance to cucumber mosaic virus does not inhibit localization and/or trafficking of the viral movement protein. Mol Plant Microbe Interactions 12: 743- 747

CARNEIRO M, VILAINE F (1993) Differential expression of the rolA plant oncogene and its effect on tobacco development. Plant J 3(6): 785-792

CARR J P, GAL-ON A, PALUKAITIS P, ZAITLIN M (1994) Replicase-mediated resistance to cucumber mosaic virus in transgenic plants involves suppression of both virus replication in the inoculated leaves and long-distance movement. Virol 199: 439-447

CHAY CA, GUNASINGE UB, DINESH-KUMAR SP, MILLER WA, GRAY SM (1996) Aphid transmission and systemic plant infection determinants of barley yellow dwarf luteovirus-PAV are contained in the coat protein readthrough and $17 \mathrm{kDa}$, respectively. Virol 219: $57-65$

CONTRERAS A (1984) Germoplasma chileno de papas (Solanum spp.). Anales Simposio Recursos Fitogenéticos. Valdivia, UACH-IBPGR N 1987: 43-75

DE HAAN P (1997) Mechanisms of RNA-mediated resistance to plant viruses. Methods in Molecular Biology Vol 81: Plant Virology protocols. Totawa, NY: Human Press Inc. pp: 533-546

DERRICK PM, BARKER H (1997) Short and long distance spread of potato leafroll luteovirus: effects of host genes and transgenes conferring resistance to virus accumulation in potato. J Gen Virol 78: 243-251

DUNWELL JM, MOYA-LEON MA, HERRERA R (2001) Transcriptome analysis and crop improvement (a review). Biol Res 34 (3-4): 153-64

GOODWIN J, CHAPMAN K, SWANEY S, PARKS TD, WERNSMAN EA, DOUGHERTY WG (1996) Genetic and biochemical dissection of transgenic RNAmediated virus resistance. Plant Cell. 8(1): 95-105

GOLEMBOSKI DB, LOMONOSSOFF GP, ZAITLIN M (1990) Plants transformed with a tobacco mosaic virus nonstructural gene sequence are resistant to the virus. Proc Natl Acad Sci USA 87: 6311-6315

GORBALENYA AE, DONCHENKO AP, BLINOV VM, KOONIN EV (1989) Cysteine proteases of positive strand RNA viruses and chymotrypsin-like serine proteases. A distinct protein superfamily with a common structural fold. FEBS Lett 243(2):103-14

GOREGAOKER SP, ECKHARDT LG, CULVER JN (2000) Tobacco mosaic virus replicase-mediated cross protection: contributions of RNA and protein-derived mechanisms. Virol 273: 267-275

GRAHAM MW, CRAIG S, WATERHOUSE PM (1997) Expression patterns of vascular- specific promoters RolC and Sh in transgenic potatoes and their use in engineering PLRV-resistant plants. Plant Mol Biol 33(4): 729-35

HERMSEN JGT, RAMANNA M.S, SAWOR Z (1981) The effect of chromosome doubling on fertility, meiotic behavior and crossability of Solanum etuberosum x S. pinnatisectum. Euphytica (Wageningen) 30: 33-39

HOEKEMA A, HIRSCH PR, HOOYKAAS PJJ, SCHILPEROORT RA (1983) A binary plant vector strategy based on separation of vir- and T-region of the Agrobacterium tumefaciens Ti-plasmid. Nature 303: 179-180

KAWCHUK LM, MARTIN RR, MCPHERSON J (1990) Resistance in transgenic potato expressing the potato leafroll virus coat protein gene. Mol Plant Microbe Interactions 3: 301-307

KOJIMA M, SHIKATA E, SUGAWARA M, MURAYAMA D (1969) Purification and electron microscopy of potato leafroll virus. Virol 39: 162- 174
KOONIN EV (1991) The phylogeny of RNA-dependent RNA polymerases of positive-strand RNA viruses. J Gen Virol 72: 2197-2206

LLAVE C, KASSCHAU KD, CARRINGTON JC (2000) Virus-encoded suppressor of posttranscriptional gene silencing targets a maintenance step in the silencing pathway. Proc Natl Acad Sci USA 97(24): 1340113406

LOGEMANN J, SCHELL J, WILLMITZER L (1987) Improved method for the isolation of RNA from plant tissues. Anal Biochem 163(1):16-20

LONGSTAFF M, BRIGNETI G, BOCCARD F, CHAPMAN S, BAULCOMBE D (1993) Extreme resistance to potato virus $\mathrm{X}$ infection in plants expressing a modified component of the putative viral replicase. EMBO Journal 12(2): 279-386

MATTHEWS REF (1991) Plant Virology. $3^{\text {rd }}$ Ed. NY: Academic Press

MILLER ED, HEMENWAY C (1998) History of coat protein-mediated protection. Methods Mol Biol 81: 25-38

MUELLER R, GIBERT J, BRIGNETI G, DAVENPORT G, BAULCOMBE DC (1995) Homology-dependent resistance: transgenic virus resistance in plants related to homology-dependent gene silencing. Plant J 7: 10011013

MURASHIGE T, SKOOG F (1962) A revised medium for rapid growth and bio assay with tobacco tissue cultures. Physiol Plant 15: 473-497

PALUKAITIS P, ZAITLIN M (1997) Replicase-mediated resistance to plant virus disease. Adv Virus Res 48:349-77

PEREDA S, EHRENFELD N, MEDINA C, DELGADO J, ARCE-JOHNSON P (2002) Evaluation of three detection methods for TMV-Cg and TMV-U1 in Arabidopsis thaliana plants growing in vitro. J Virol Methods 90(2): 135-142

RUIZ MT, VOINNET O, BAULCOMBE DC (1998) Initiation and maintenance of virus-induced gene silencing. Plant Cell 10: 937-946

SIJEN T, KOOTER JM (2000) Post-transcriptional genesilencing: RNAs on the attack or on the defense? Bioessays 22(6): 520-31

SOKOLOVA M, PRÜFER D, TACKE E, RHODE W (1997) The potato leafroll virus $17 \mathrm{~K}$ movement protein is phosphorylated by a membrane-associated protein kinase from potato with biochemical features of protein kinase C. FEBS Lett. 400: 201- 205

TACKE E, SALAMI F, RHODE W (1996) Genetic engineering of potato for broad-spectrum protection against virus infection. Nat Biotech 14: 1597-1601

TENLLADO F, GARCÍA-LUQUE I, SERRA MT, DÍAZRUIZ JR (1996) Resistance to pepper mild mottle tobamovirus conferred by the $53 \mathrm{kDa}$ gene sequence in transgenic plants does not require expression of the wild type 54kDa protein. Virol 219: 330- 335

THOMAS PE, LAWSON EC, ZALEWSKI JC, REED GL, KANIEWSKI WK (2000) Extreme resistance to Potato leafroll virus in potato cv. Russet Burbank mediated by the viral replicase gene. Virus Res 71 (1-2): 49-62

VAN DER WILK F, HUISMAN MJ, CORNELISSEN BJC, HUTTINGA H, GOLDBACH R (1989) Nucleotide sequence and organization of potato leafroll virus genomic RNA. FEBS Lett 245 (1,2): 51-56

VAN DER WILK F, HOUTERMAN P, MOLTHOFF J, HANS F, DEKKER B, VAN DEN HEUVEL J, HUTTINGA H, GOLDBACH R (1997) Expression of the potato leafroll virus ORF0 induces viral-diseaselike symptoms in transgenic potato plants. Mol Plant Microbe Interactions 10(2): 153-159 
VAUCHERET H, FAGARD M (2001) Transcriptional gene silencing in plants: targets, inducers and regulators. Trends Genet 17(1): 29-35

VÁZQUEZ ROVERE C, ASURMENDI S, HOPP HE (2001) Transgenic resistance in potato plants expressing potato leaf roll virus (PLRV) replicase gene sequences is RNAmediated and suggests the involvement of posttranscriptional gene silencing. Arch Virol 146(7): 1337-53
WATERHOUSE PM, SMITH NA, WANG MB (1999) Virus resistance and gene silencing: killing the messenger. Trends Plant Sci. 4(11): 452-457

WINTERMANTEL WM, ZAITLIN M (2000) Transgene transability increases effectiveness of replicasemediated resistance to Cucumber mosaic virus. J Gen Virol 81: 587- 595 